\title{
Influence of Three-Dimensional Stress Field Variation on Fracture Evolution Characteristics of a Roof
}

\author{
Xuyang Shi $\mathbb{D}^{1,2}$ Zhaolin Li $\mathbb{D}^{1,2}$ Qingxiang Cai $\mathbb{D}^{1,2}$ Wei Zhou $\mathbb{D}^{1,2}$ and Wenshuai Li $\mathbb{D}^{3}$ \\ ${ }^{1}$ School of Mines, China University of Mining and Technology, Xuzhou, Jiangsu 221116, China \\ ${ }^{2}$ State Key Laboratory of Coal Resources and Safe Mining, China University of Mining and Technology, Xuzhou, \\ Jiangsu 221116, China \\ ${ }^{3}$ State Key Laboratory for Geomechanics and Deep Underground Engineering, China University of Mining and Technology, Xuzhou, \\ Jiangsu 221116, China
}

Correspondence should be addressed to Wei Zhou; loutian1982@126.com

Received 26 June 2020; Revised 10 November 2020; Accepted 30 November 2020; Published 28 December 2020

Academic Editor: Yingchun Li

Copyright (C) 2020 Xuyang Shi et al. This is an open access article distributed under the Creative Commons Attribution License, which permits unrestricted use, distribution, and reproduction in any medium, provided the original work is properly cited.

\begin{abstract}
Excavation disturbance on the dynamic variation of the three-dimensional stress field is the main cause for the dynamic disasters of the surrounding rock mass of the roof. The stress condition in the surrounding rock mass of the roof during entry excavation and its impact on entry stability are systemically studied in this study. It is found that the surrounding rock mass of the roof is mainly influenced by the combined effect of the stress unloading and stress transference induced by entry excavation. A servocontrolled true triaxial material testing system is used to conduct the true triaxial loading and unloading experiments of rocks under different stress paths. The influence of different stress paths, especially the variation of the principal stress direction, on the mechanical characteristics and fracture characteristics of rocks is investigated. The results indicate that the variation of the principal stress direction has a significant impact on the macroscopic fracture characteristics of the rock. The main macroscopic fracture plane of the rock highly depends on the intermediate principal stress. The fracture evolution of the roof rock mass during entry excavation is analyzed. The results show that the change of the three-dimensional stress field induces the formation of complex fracture networks in the surrounding rock mass of the roof. The roof is likely to dislocate horizontally and collapse. The corners of the entry are seriously damaged. Based on the above findings, a support scheme is proposed to maintain the stability of a gob-side entry. The field experience suggests that the support scheme can achieve good results.
\end{abstract}

\section{Introduction}

Dynamic disasters, such as the serious deformation and collapse of the entry roof, have always been major issues restricting the safe, effective mining of coal resources in China $[1,2]$. The entry roof tends to fail and become more instable with the increase in mining intensity and mining depths [3]. The failure and instability of the roof result from the formation of the fracture zone in the surrounding rock mass of the entry $[4,5]$. It is of great significance in the aspects of theoretical analysis and field applications to understand the fracture pattern and its evolution in the surrounding rock mass of the roof in order to maintain the stability of the roof and prevent dynamic disasters [6].
The excavation of mining entries disturbs the in situ stress balance [7] and induces the dramatic change [8] and dynamic adjustment of the stress filed in the roof [9]. This normally leads to the serious deformation and failure of the roof. The mechanical behaviour of the entry roof is closely related to the disturbance caused by entry excavation [10]. Therefore, it is necessary to consider the influence of the stress change in the surrounding rock mass of the entry roof and systematically study the stress disturbance process caused by entry excavation and the mechanical response of the rock mass [11]. Previous studies mainly consider the effect of the change of the vertical stress (i.e., the abutment stress) on the stability of the roof and simply assume that the deformation and failure of the roof result from the onedimensional loading. Based on field measurement and 
numerical modelling results, $[12,13]$ found that the obvious dynamic adjustment of the three-dimensional stress state in the surrounding rock mass occurs in the driving process of the entry. The individual or the simultaneous variation of each stress component in the three-dimensional stress state is likely to cause the deformation and fracture of the surrounding rock mass.

Many researchers have carried out triaxial compression tests to reveal the mechanical behaviour and the failure process of the surrounding rock mass of the entry under the influence of the complicated three-dimensional stress evolution caused by the disturbance of excavation [14]. These studies mainly focused on the effects of the loading and unloading process in the conventional triaxial compression tests on the strength [15], deformation [16], and failure modes [17] of rocks. Nevertheless, due to the inherent shortcoming of the conventional triaxial compression test that ignores the influence of the intermediate principal stress [18], only the axial stress that differs from the lateral stress can be applied to the cylindrical rock specimen in the laboratory test [19]. Hence, only the strength and deformation characteristics of the rock under the axisymmetric stress condition can be reflected. This is unrepresentative of the stress condition that the rock normally encounters in the realistic situation $\left(\sigma_{1} \neq \sigma_{2} \neq \sigma_{3}\right)$ and differs from the stress evolution characteristics of the entry rock mass induced by excavation disturbance $[20,21]$. Based on the three-dimensional stress evolution in the entry roof at the mine site, experimental studies on rocks under true triaxial stress paths can more accurately simulate the failure evolution process of the roof disturbed by gob-side entry driving and disclose the failure mechanism [22]. This is significant for the stability control of the entry roof.

In addition, the traditional theories always considered that the maximum principal stress in the roof strata induced by excavation disturbance has the vertical orientation [23]. Only the stress concentration factor of the abutment stress in the vertical direction was involved in the analysis of the stress state in the surrounding rock mass of the entry influenced by mining excavation [24, 25]. In fact, besides the change of the magnitudes of the principal stresses, the change of the orientations of the principal stresses also occurs during the excavation and construction of underground spaces (e.g., entries) [26, 27]. However, the rotation of the principal stresses in the roof strata is normally ignored in previous studies $[28,29]$. Many experimental results in civil engineering indicated that the rotation of the principal stress orientations (assuming that the magnitudes of the principal stresses remain constant) leads to the obvious plastic deformation of the soil [30]. Hence, the complicated evolution of the stress path and the stress orientation induced by entry excavation results in the damage and degradation of the mechanical parameters of the roof. Besides, the dynamic damage evolution process is the fundamental cause for the deformation and fracture of the roof rock mass of the entry.

In view of this, the gob-side entry driving activity at the Dongtan Coal Mine (owned by Yankuang Group) is taken as the engineering background to systematically study the influence of entry excavation on the principal stress path and the stress principal orientation in the roof rock mass. The mechanism of the dynamic disaster of the roof induced by gob-side entry driving is revealed. The related control technology of the roof rock mass is proposed based on the results. The engineering experience at the Dongtan Coal Mine also offers a reference to the support design of the entries with similar conditions.

\section{Engineering Background and Numerical Model}

The Dongtan Coal Mine is located in Shandong Province, China (Figure 1(a)). The mining entry in the $3 \#$ coal seam at the Dongtan Coal Mine is excavated by gob-side entry driving. The coal pillar between the gob-side entry and the previous panel has a width of $3 \mathrm{~m}$. The dip angle of the 1306 working face in the $3 \#$ coal seam ranges from $0^{\circ}$ to $12^{\circ}$ with an average of $6^{\circ}$ (Figure $1(\mathrm{~b})$ ). The coal seam has an average thickness of $8.8 \mathrm{~m}$. The 1306 tail entry is located at the $-660 \mathrm{~m}$ level and is close to the goaf of the 1305 working face (which is at the south of the 1306 tail entry). The entry has a trapezoidal cross section $(4.8 \mathrm{~m}$ wide at the roof and $5.0 \mathrm{~m}$ wide at the floor) with a height of $4 \mathrm{~m}$. In situ stress monitoring was performed in the head entry by the stress relief method. The maximum horizontal in situ stress $\left(\sigma_{\mathrm{H}}\right)$, the minimum horizontal stress $\left(\sigma_{\mathrm{h}}\right)$, and the vertical in situ stress $\left(\sigma_{\mathrm{V}}\right)$ are $19.15 \mathrm{MPa}, 10.02 \mathrm{MPa}$, and $14.64 \mathrm{MPa}$, respectively.

To study the influence of gob-side entry excavation on the principal stress change and the damage of the roof, the numerical modelling software ABAQUS (based on the finite element method) is used to establish the numerical model in this study (Figure 2(a)). The locations of the mining entries in the 1306 working face in the numerical model are given in Figure 2(b). Both the 1305 head entry and the 1306 tail entry have dimensions of $5 \mathrm{~m}$ (in width) $\times 4 \mathrm{~m}$ (in height). The width of the coal pillar is $3 \mathrm{~m}$. The vertical displacement at the bottom boundary of the model is fixed. A uniform stress of $15 \mathrm{MPa}$ is applied to the top boundary of the model to simulate the overburden stress (the thickness of the overburden rock layers in the numerical model is $660 \mathrm{~m}$ ). The maximum horizontal in situ stress is $19.5 \mathrm{MPa}$, which is parallel to the entry axis. The minimum horizontal in situ stress is $10.5 \mathrm{MPa}$, which is perpendicular to the entry axis. The strain softening model based on the Mohr-Coulomb criterion is used in the numerical simulation. The mechanical parameters of the coal seam and the roof and floor strata in the numerical model are listed in Table 1. Compared with the field measurement results, the numerical simulation can provide good results (Figure 3 ), which shows the reliability of the numerical model.

Three monitoring points are arranged in the roof rock mass, which are $0 \mathrm{~m}, 4 \mathrm{~m}$, and $8 \mathrm{~m}$ above the roof, respectively (Figure 4 ). The change of the principal stresses in the roof rock mass is provided in Figure 5. When the working face is $20 \mathrm{~m}$ in front of the monitoring section, the rock mass close to the roof suffers from the influence of entry excavation. When the working face is $5 \mathrm{~m}$ to the monitoring section, the excavation disturbance becomes quite obvious. Clear 


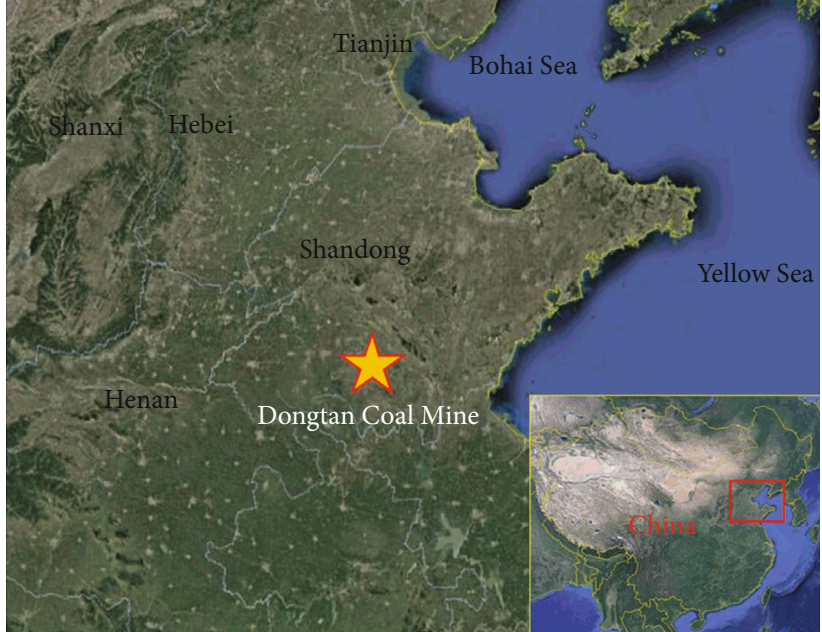

(a)

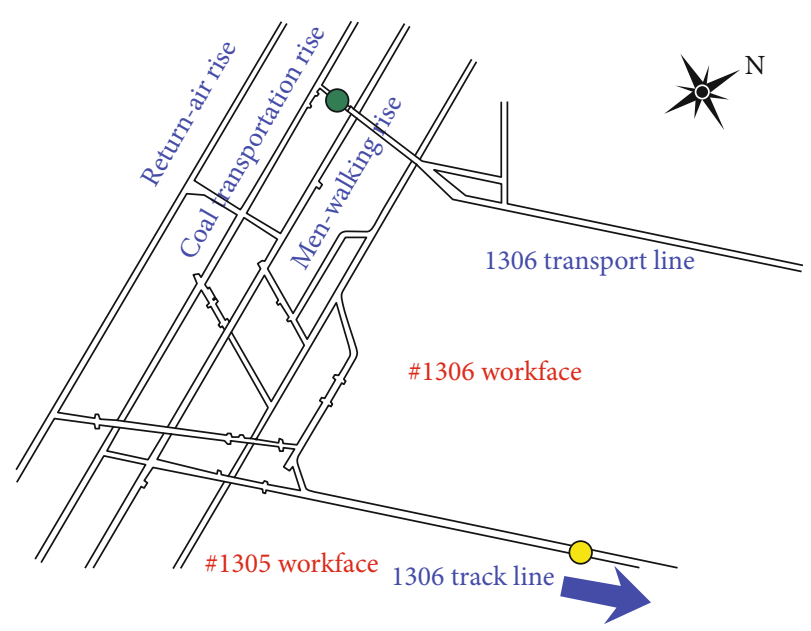

In situ stress measurement station

Displacement monitoring station

(b)

Figure 1: (a) Location of the Dongtan Coal Mine, Shandong, China. (b) Plane view of working face arrangement.

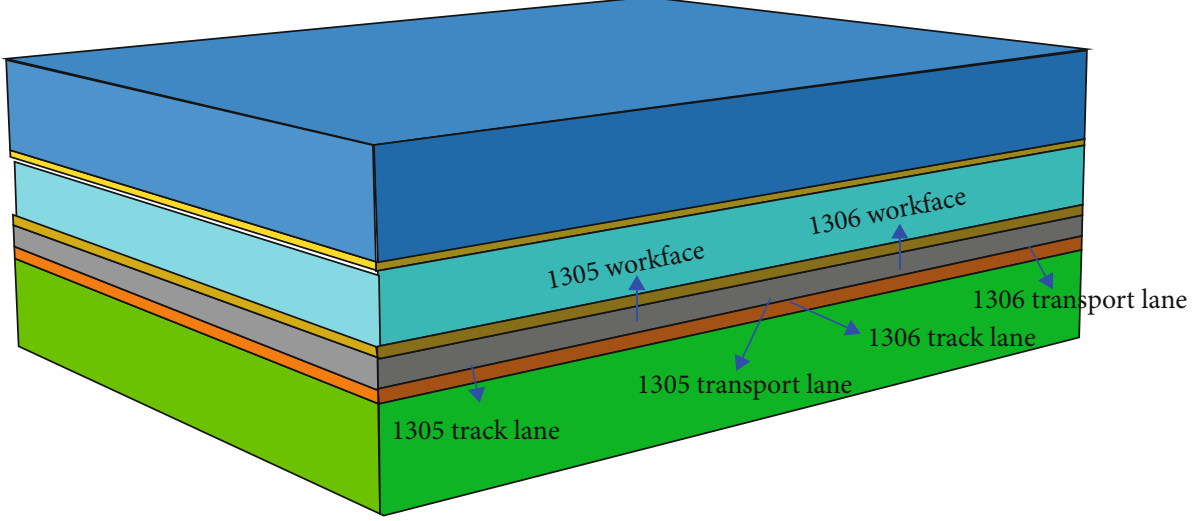

(a)

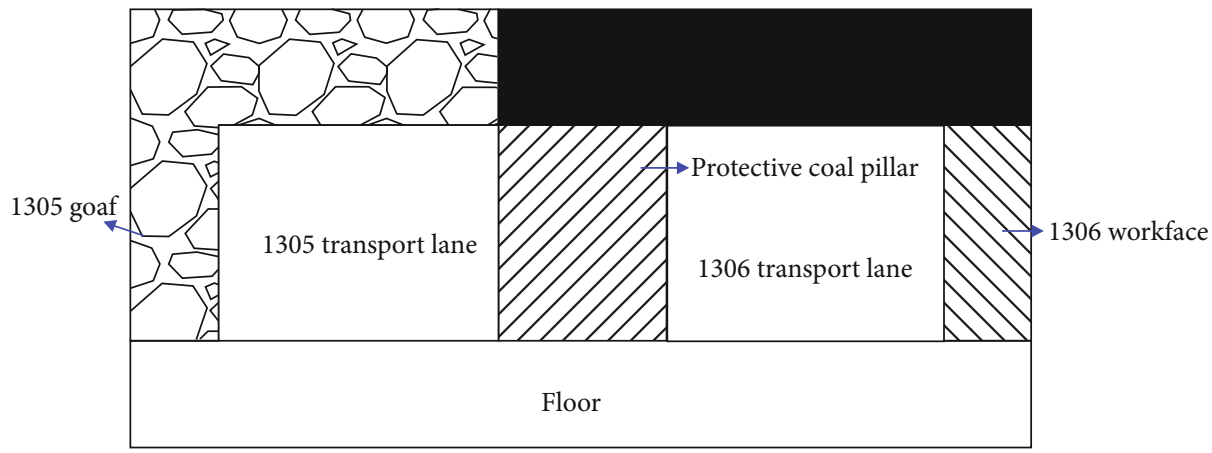

(b)

Figure 2: (a) Numerical model. (b) Schematic of the mining entries in the 1306 working face.

unloading processes of the three principal stresses occur in the elements at the roof surface. The magnitudes of $\sigma_{1}$ and $\sigma_{3}$ increase first and then decrease, while the $\sigma_{2}$ magnitude is continuous. The change of the principal stresses at the monitoring points $4 \mathrm{~m}$ and $8 \mathrm{~m}$ above the roof is similar to that at the roof surface. The excavation disturbance becomes weaker at the rock mass away from the entry roof. When the working face is $10 \mathrm{~m}$ behind the monitoring section, the three principal stresses in the roof elements gradually stabilize. This suggests that the influence of the entry excavation on the monitoring section terminates and the stress condition in the roof rock mass redistributes to the equilibrium state. 
TABLE 1: Mechanical parameters of coal seam and rock strata.

\begin{tabular}{|c|c|c|c|c|c|c|c|c|}
\hline Stratum & Lithology & $\begin{array}{c}\text { Thickness } \\
(\mathrm{m})\end{array}$ & $\begin{array}{c}\text { Elastic } \\
\text { modulus } \\
(\mathrm{GPa})\end{array}$ & $\begin{array}{l}\text { Poisson } \\
\text { ratio }\end{array}$ & $\begin{array}{l}\text { Density } \\
\left(\mathrm{kg} / \mathrm{m}^{3}\right)\end{array}$ & $\begin{array}{l}\text { Internal } \\
\text { friction } \\
\text { angle }\left({ }^{\circ}\right)\end{array}$ & $\begin{array}{c}\text { Initial } \\
\text { cohesion } \\
(\mathrm{MPa})\end{array}$ & $\begin{array}{c}\text { Residual } \\
\text { cohesion } \\
(\mathrm{MPa})\end{array}$ \\
\hline \multirow{4}{*}{ Roof } & Sandstone & 110 & 15 & 0.3 & 2560 & 25 & 3 & 2 \\
\hline & Mudstone & 2 & 8 & 0.35 & 2480 & 18 & 1.2 & 1 \\
\hline & Middle-fine sandstone & 20 & 9 & 0.3 & 2560 & 24 & 1.3 & 1.1 \\
\hline & Argillaceous siltstone & 3 & 8 & 0.36 & 2480 & 18 & 1.1 & 0.8 \\
\hline Coal seam & $3 \#$ coal & 8.5 & 7 & 0.35 & 1400 & 16 & 1 & 0.6 \\
\hline \multirow{2}{*}{ Floor } & Siltstone & 4 & 8 & 0.35 & 2560 & 18 & 1.1 & 0.8 \\
\hline & Fine sandstone & 32.5 & 12 & 0.3 & 2560 & 30 & 5 & 4 \\
\hline
\end{tabular}

According to elastic mechanics, when the tangential stress at a surface of an arbitrary point in a threedimensional space equals to zero, the normal stress at this surface is considered one of the principal stresses at this point and the normal direction of this surface is also the direction of the principal stress. The direction of the principal stress can be calculated by [31]

$$
\left\{\begin{array}{c}
\left(\sigma_{x}-\sigma\right) l+\tau_{x y} m+\tau_{y z} n=0 \\
\tau_{x y} l+\left(\sigma_{y}-\sigma\right) m+\tau_{y z} n=0 \\
\tau_{x z} l+\tau_{y z} m+\left(\sigma_{z}-\sigma\right) n=0 \\
l^{2}+m^{2}+n^{2}=1
\end{array}\right.
$$

where $\sigma_{x}$ is the stress component in the $x$-axis, $\sigma_{y}$ is the stress component in the $y$-axis, $\sigma_{z}$ is the stress component in the $z$ -axis, $\tau_{x y}$ is the shear stress at the $x-y$ surface, $\tau_{x z}$ is the shear stress at the $x$ - $z$ surface, $\tau_{y z}$ is the shear stress at the $y$ - $z$ surface, $l$ is the cosine of the angle between the normal line of the surface and the $x$-axis, $m$ is the cosine of the angle between the normal line of the surface and the $y$-axis, $n$ is the cosine of the angle between the normal line of the surface and the $z$-axis, and $\sigma$ is the principal stress tensor. According to the elastic mechanics theory, the parallel Equations (1) and (2) can be used to obtain the cosines $l_{1}, m_{1}$, and $n_{1}$ of the corresponding directions of the principal stress $\sigma_{1}$. The corresponding direction cosine of the principal stresses $\sigma_{2}$ and $\sigma_{3}$ can also be obtained.

The change of the principal stress directions in the roof rock mass at different stages during entry excavation is given in Figure 6. The entry axis is perpendicular to the paper as shown in Figure 6 . The change of the angle between the principal stress at the top surface of the monitoring element and the vertical direction is provided in Figure 7. When the working face moves from the location $5 \mathrm{~m}$ in front of the monitoring surface to the location $5 \mathrm{~m}$ behind the monitoring surface, the principal stress direction in the entry roof rock mass shows dramatic variation. The principal stress direction at the roof surface exhibits obvious rotation, and the change of the principal stress directions at the monitoring elements $4 \mathrm{~m}$ and $8 \mathrm{~m}$ above the roof becomes minor. Nevertheless, the reverse of the principal stress direction is observed at all the three monitoring points. The principal stresses at the monitoring point $8 \mathrm{~m}$ above the roof change earlier than those at the monitoring point $4 \mathrm{~m}$ above the roof. This indicates that the entry excavation leads to the transference of the principal stress from the rock mass away from the roof to the rock mass close to the roof.

\section{Fracture Characteristics of Rocks under Different Stress Paths}

3.1. Stress Path Design. The numerical simulation results in Section 2 show that the roof rock mass sustains complicated stress paths due to the disturbance of the entry excavation. The mechanical characteristics of rocks are closely related to the stress paths they undergo. The fracture characteristics and the fracture mechanism of rocks under complex stress paths can be more accurately described by laboratory experiments on rock specimens under different stress paths. The results can provide a theoretical basis for the entry support at the mine site. To study the fracture characteristics of the roof rock and analyze its fracture mechanism, the following three typical triaxial stress paths are proposed in this section based on the stress paths in the roof rock mass (Table 2).

The underground rock mass is under the in situ stress condition when the entry is unexcavated. With the advance of the working face, the principal stresses in the rock masses with various distances to the entry surface exhibit a certain difference. The maximum principal stress shows variation during the entry excavation and is hence assumed to be constant in this study. The unloading of the intermediate principal stress and the minimum principal stress could occur due to different geotechnical conditions and the variation of the stress conditions. Note that the results in Figures 6 and 7 suggest that entry excavation results in the obvious change of the stress condition in the roof rock mass, especially the exchange of the intermediate principal stress and the minimum principal stress. This is found at all the three monitoring points in the roof rock mass when the working face moves towards the monitoring section (from the location $5 \mathrm{~m}$ in front of the monitoring section). This section is aimed at investigating the influence of this stress condition variation on the mechanical characteristics and the fracture characteristics of the rock.

3.2. Specimen Selection and Experimental Schemes. The red sandstone is selected for the experimental study, which 


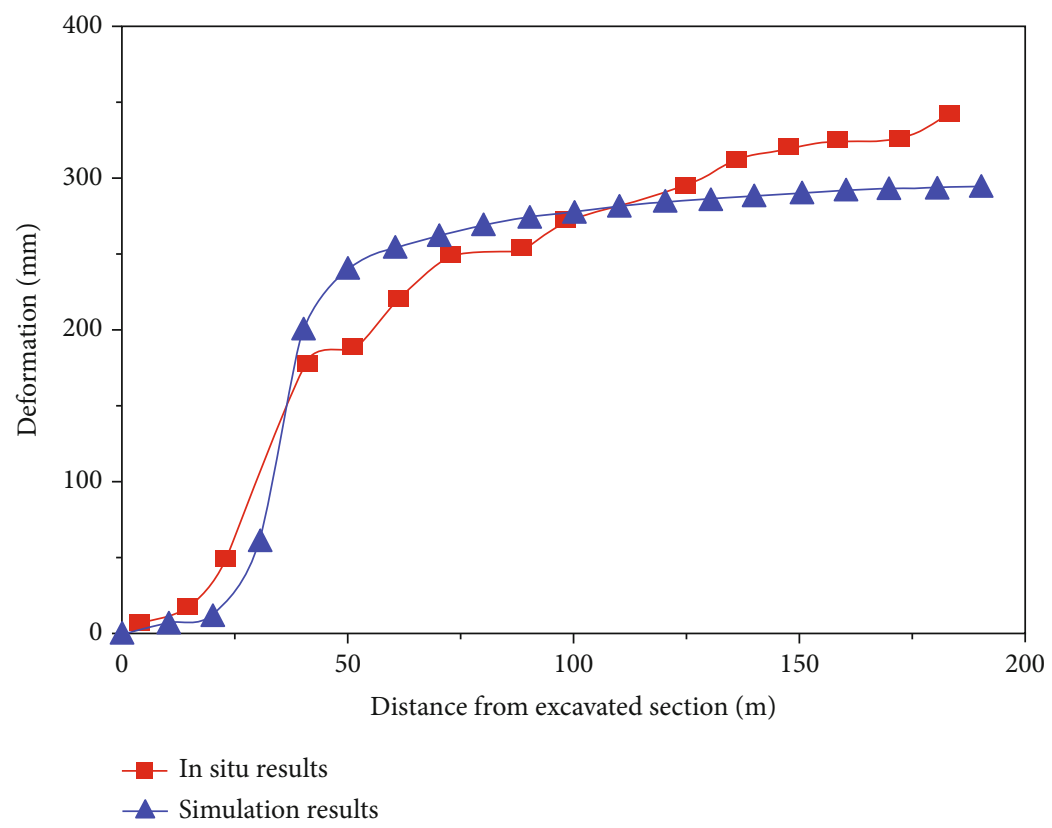

(a)

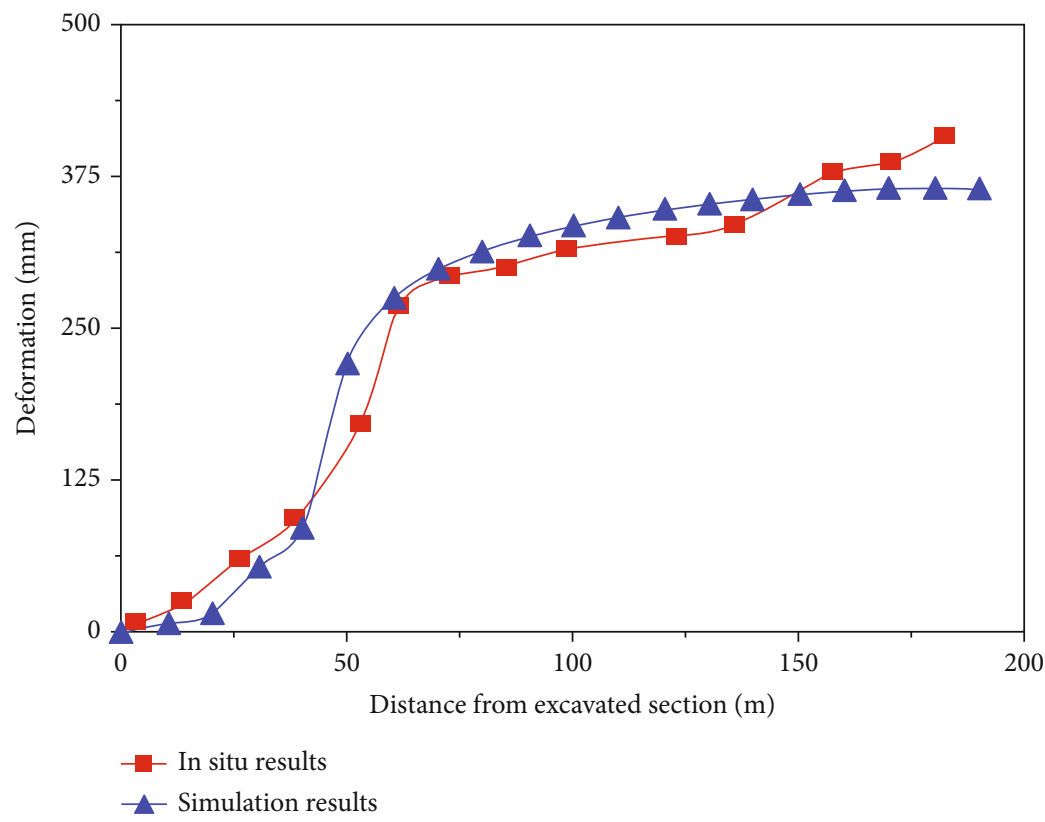

(b)

Figure 3: Comparison between numerical simulation results and in situ measurement results of entry deformation: (a) roof-to-floor convergence; (b) side-to-side convergence.

mainly consists of feldspar and quartz. The sandstone specimen is medium-grained with grain sizes from $0.10 \mathrm{~mm}$ to $0.35 \mathrm{~mm}$ (Figure 8). Its average density is $2380 \mathrm{~kg} / \mathrm{m}^{3}$. Each specimen is cubic with dimensions of $50 \mathrm{~mm}$ (in length) $\times$ $50 \mathrm{~mm}$ (in width) $\times 100 \mathrm{~mm}$ (in height). A grinder is used to flatten the surface of each specimen end.

A servo-controlled true triaxial material testing system [32] is used to conduct the true triaxial compression tests under different loading and unloading stress paths. The influence of three stress paths on the fracture characteristics of the specimen is studied. Each triaxial test has two stages, including loading the specimen to the expected in situ stress condition (stage 1) and the loading and unloading stage (stage 2) (Figure 9). To get the final fracture pattern of the specimen, the confining pressure and the constant axial stress are increased. The detailed loading and unloading schemes are given as follows.

The three loading and unloading schemes have the same first loading stage (i.e., stage I). First, the specimen is loaded to a hydrostatic stress condition $\left(\sigma_{1}=\sigma_{2}=\sigma_{3}=20 \mathrm{MPa}\right)$ at 


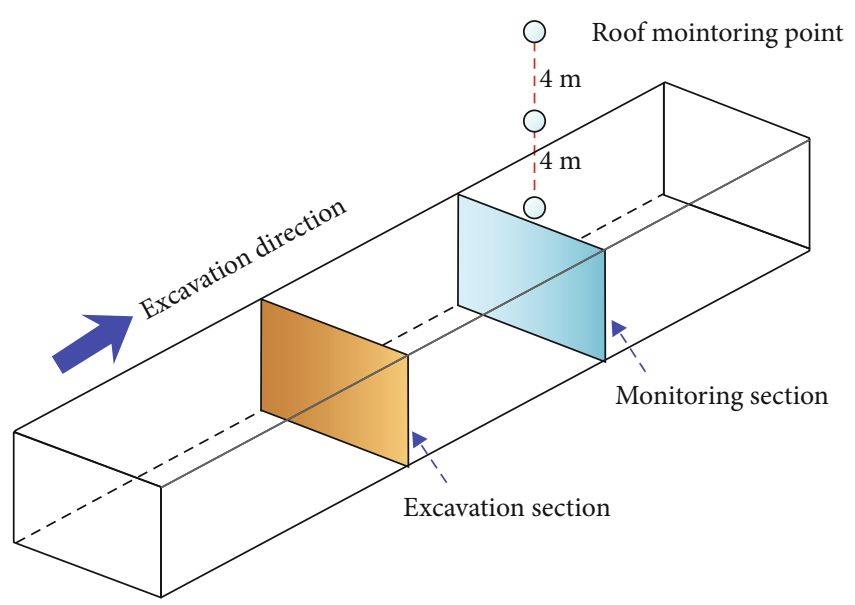

FIgURE 4: Locations of stress monitoring points.

a velocity of $0.1 \mathrm{MPa} / \mathrm{s}$. Then, $\sigma_{3}$ remains constant and $\sigma_{1}$ and $\sigma_{2}$ are increased at the same velocity until $\sigma_{2}$ reaches the expected magnitude $\left(\sigma_{1}=\sigma_{2}=40 \mathrm{MPa}\right)$. After that, $\sigma_{2}$ and $\sigma_{3}$ are kept constant and $\sigma_{1}$ is increased to the predesigned magnitude. Note that the specimen has the average peak strength of about $615 \mathrm{MPa}$ when $\sigma_{2}$ and $\sigma_{3}$ are $40 \mathrm{MPa}$ and $20 \mathrm{MPa}$, respectively, based on the true triaxial test results. Hence, the $\sigma_{1}, \sigma_{2}$, and $\sigma_{3}$ magnitudes in the designed in situ stress condition of the specimen are $490 \mathrm{MPa}(80 \%$ of the peak strength), $40 \mathrm{MPa}$, and $20 \mathrm{MPa}$, respectively.

In the second stage (stage II), for path I, the $\sigma_{1}$ magnitude remains constant and $\sigma_{2}$ and $\sigma_{3}$ are decreased at a velocity of $0.1 \mathrm{MPa} / \mathrm{s}$ until the specimen fails. In path II, both $\sigma_{1}$ and $\sigma_{3}$ are kept constant and $\sigma_{2}$ is decreased at a velocity of $0.1 \mathrm{MPa} / \mathrm{s}$ until the specimen fails. As shown in Figure 9, $\sigma_{2}$ will equal to $\sigma_{3}$ in the unloading process of $\sigma_{2}$ (point $e$ in Figure 9). After that, $\sigma_{2}$ and $\sigma_{3}$ exchange with each other. In path III, both $\sigma_{1}$ and $\sigma_{2}$ remain unchanged and $\sigma_{3}$ is decreased at a velocity of $0.1 \mathrm{MPa} / \mathrm{s}$ until the specimen fails.

3.3. Characteristics of Strength and Deformation. Figure 10 shows the change of the three principal stresses with the loading time of the specimen under the second stress path (path II). The unloading stage (the $d f$ stage in Figure 9) is analyzed in this section, which includes the prefailure stage and the postfailure stage. The three principal stress components of the specimen change linearly with the unloading time in the prefailure stage. This suggests that all the three principal stresses vary according to the predesigned stress path. The $\sigma_{1}$ magnitude drops abruptly when the rock fails. Obvious brittle failure of the specimen is observed. In Figure 10, with the gradual decrease of $\sigma_{2}$, its magnitude equals to that of $\sigma_{3}$ (point $e$ in Figure 9). After that, $\sigma_{2}$ exchanges with $\sigma_{3}$, which means that the intermediate principal stress becomes the minimum principal stress. The existence of the intersection point $e$ in Figure 9 could lead to the variation of the fracture characteristic of the specimen.

Since all the three principal stresses vary during the loading and unloading of the specimen, the octahedral shear stress $\tau_{\text {oct }}$ in Equation (3) is used to generalize the strength characteristic of the specimen [33]:

$$
\tau_{\mathrm{oct}}=\frac{1}{3} \sqrt{\left(\sigma_{1}-\sigma_{2}\right)^{2}+\left(\sigma_{2}-\sigma_{3}\right)^{2}+\left(\sigma_{1}-\sigma_{3}\right)^{2}} .
$$

As shown in Figure 11(a), the octahedral shear stresses of the specimens undergo three different unloading stress paths that almost coincide with each other in the prefailure stage and drop abruptly (i.e., brittle failure) in the postfailure stage. The time period between the start of the unloading process and the strength failure of the specimen is termed prefailure unloading duration. The specimens under three unloading paths undergo different prefailure unloading duration, in which the specimen in path I has the shortest prefailure unloading duration and the specimen in path II undergoes the longest. The strains of the specimen under different stress paths are plotted against the loading time in Figure 11(b). The three principal strains of the specimen increases almost linearly against the unloading time at the early stage of the unloading process. Then, the strain rate gradually increases as the unloading time increases. The three principal strains increase, following the power function, in the postfailure stage.

3.4. Acoustic Emission Characteristics. Figure 12(a) gives the typical characteristics of the basic AE parameters of the specimen under path III (the other tests have a similar feature). The $\mathrm{AE}$ events are quite active in the early stages of the unloading processes of the specimen under two different stress paths. This suggests that the internal microcracks initiate and propagate before the unloading process commences. The number of the AE events is below 100 before the strength failure of the specimen, which indicates that the microcracks inside the specimen propagate stably. The amount of the $\mathrm{AE}$ events increases dramatically in a short time when the peak strength of the specimen is reached, which indicates the start of the unstable propagation of the microcracks and the formation of the macroscopic failure planes.

Figure 12(b) gives the variation of the cumulative $\mathrm{AE}$ events against the unloading time under different stress paths [34], which is similar to that of the specimen deformation. The AE events increase stably at the early stage of the unloading process (before the strength failure of the specimen), which suggests the slow propagation of the internal microcracks. The increase in the AE events of the specimen under path II is the slowest compared with that under the other two stress paths. The characteristics of the specimen tend to become that under conventional triaxial compression as the $\sigma_{2}$ magnitude decreases. The intermediate principal stress applies obvious confining to the specimen, and the microcracks develop slowly. The number of the AE events in the specimen under path III rises more quickly since the differential stress between $\sigma_{2}$ and $\sigma_{3}$ increases during the unloading of $\sigma_{3}$. This enhances the damage effect of the intermediate principal stress and leads to the faster propagation of the microcracks. The AE events in the specimen under the first stress path are highly active, and the microcracks propagate quite fast at the early stage of the unloading process. This indicates that the simultaneous unloading of $\sigma_{2}$ and $\sigma_{3}$ 


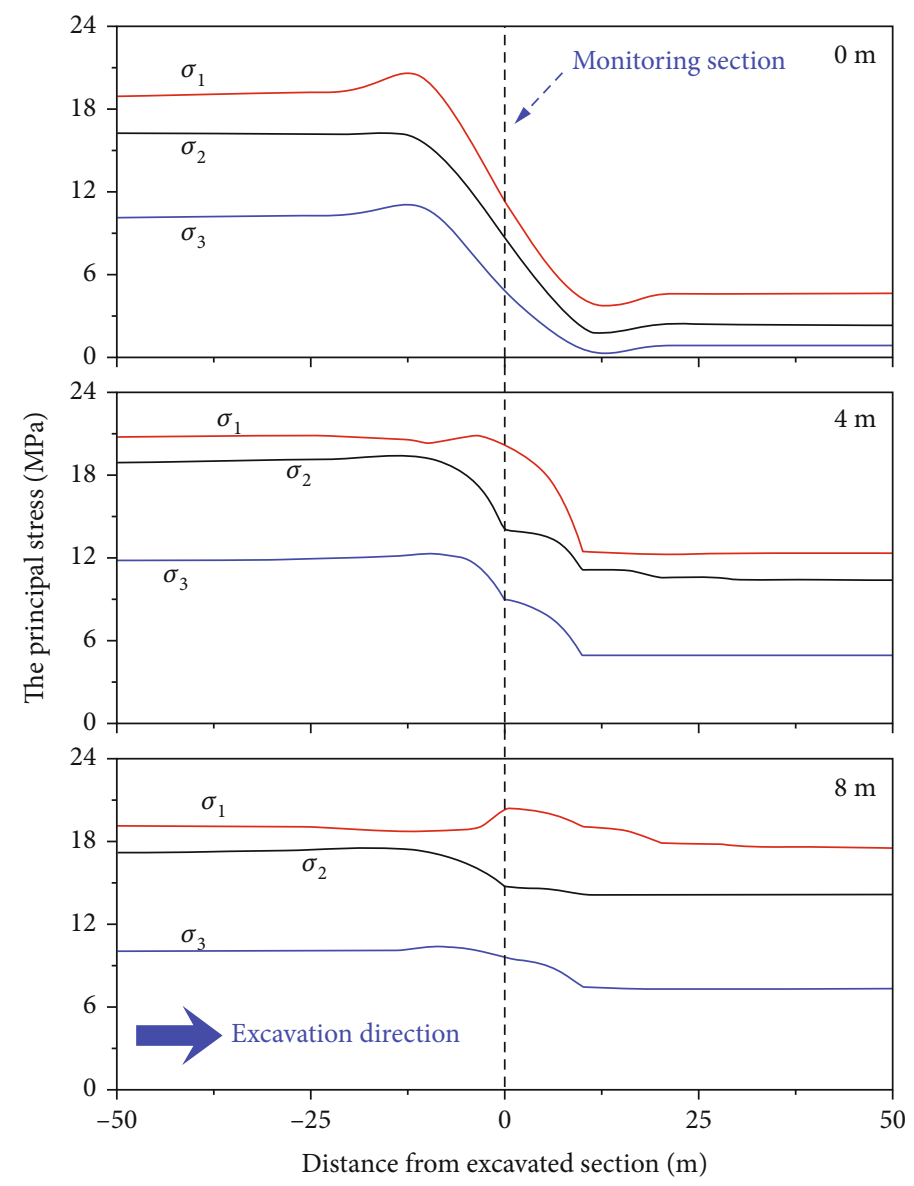

FIGURE 5: Variation of principal stresses.

$8 \mathrm{~m}$
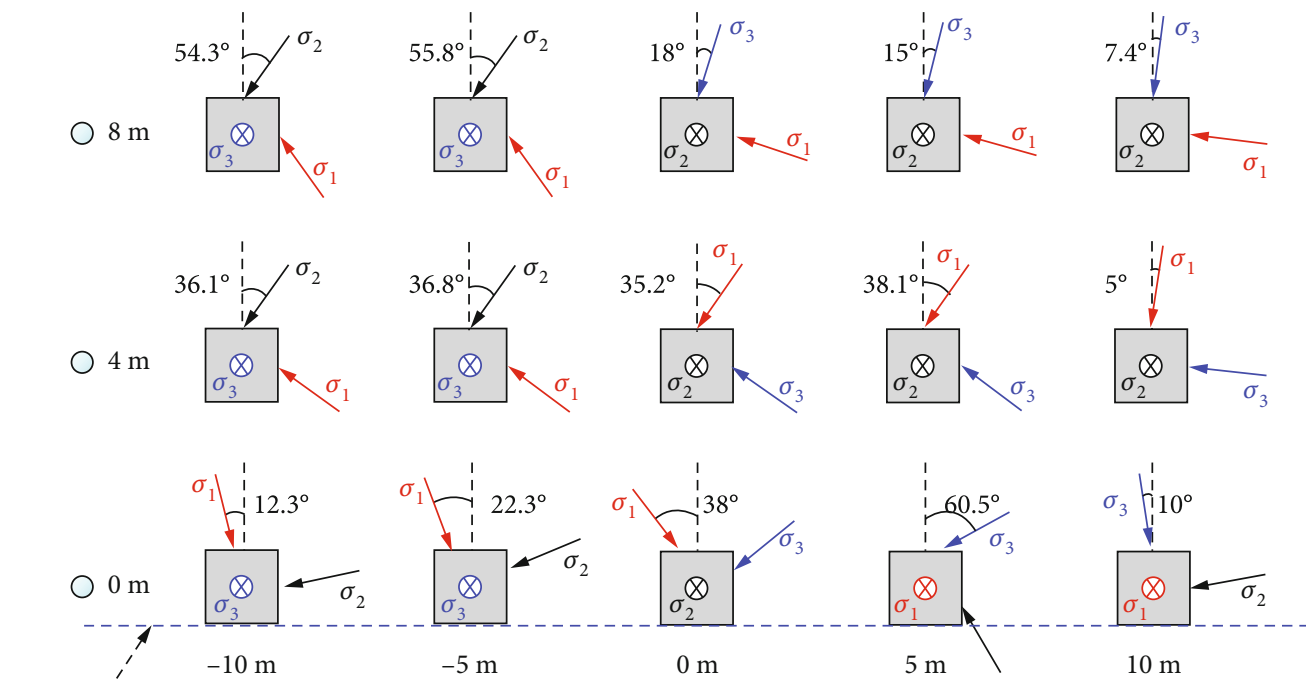

Roof surface

Excavation direction

FIGURE 6: Variation of principal stress directions in the entry roof.

exaggerates the propagation of the microcracks and weakens the strength of the rock. When the axial stress reaches the peak strength, dramatic increase in the AE events is found in the specimens under all the three stress paths, which shows the brittle failure characteristic of the specimen.
3.5. Fracture Characteristics. Table 3 presents the macroscopic fracture characteristics of the specimens under different loading and unloading stress paths. The $\sigma_{2}$ direction and the $\sigma_{3}$ direction in Table 3 are the initial stress direction of the specimen. Along the $\sigma_{2}$ direction, the macroscopic failure 


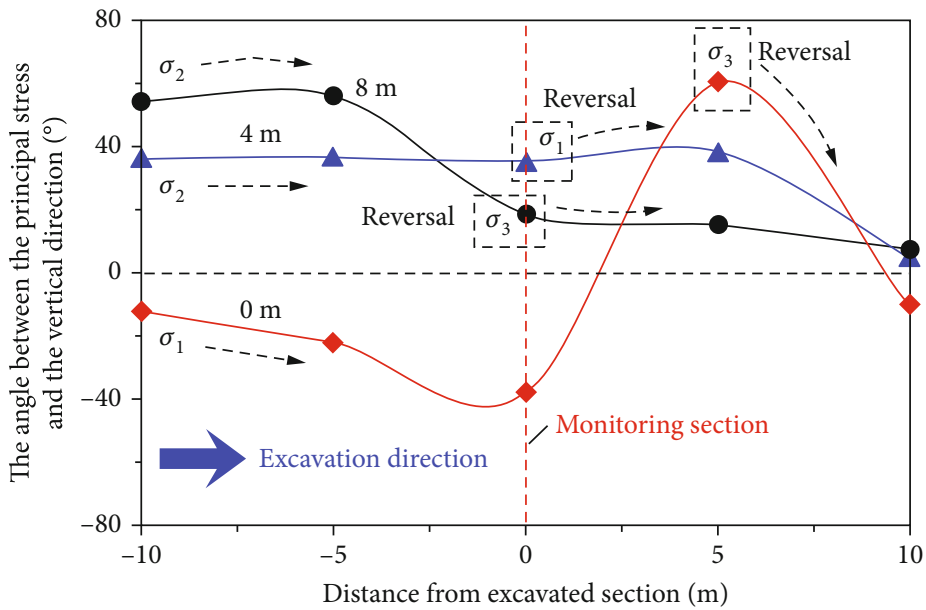

Figure 7: Variation of the angle between the principal stress and the vertical direction.

TABLE 2: Typical stress paths.

Stress path

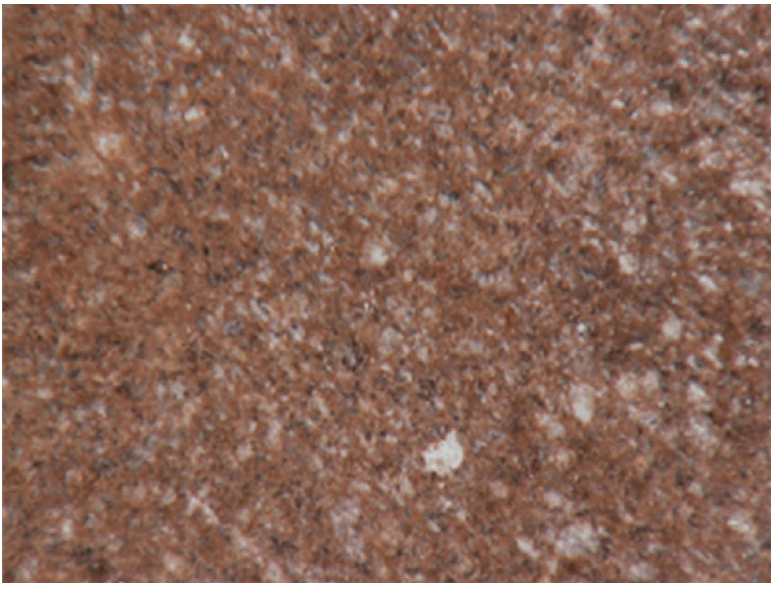

(a)

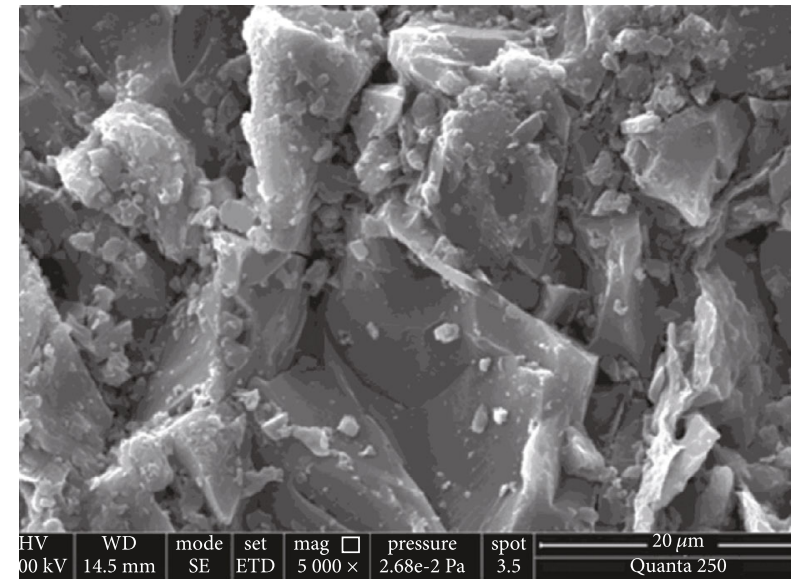

(b)

FIgURE 8: Optical microscopy and SEM features of red sandstone.

plane has a "V" shape that stretches through the specimen. An obvious brittle failure characteristic is found. Along the $\sigma_{3}$ direction, a quite dense " $\mathrm{X}$ "-shaped fracture network is observed in the specimen under path II, while no obvious macroscopic fracture is found in the specimens under the other two stress paths. This indicates that if the intermediate principal stress is always higher than the minimum principal stress in the specimen in the unloading process, the macro- scopic failure plane only propagates along the $\sigma_{2}$ direction and the specimen looks intact along the $\sigma_{3}$ direction.

Once the stress condition in the specimen has a notable change, such as the reverse of $\sigma_{2}$ and $\sigma_{3}$ in Figures 6 and 7, the fracture characteristics of the specimen will be highly influenced. Hence, this section focuses on the second stress path (path II) in which the $\sigma_{2}$ and $\sigma_{3}$ directions exchange with each other. At the early stage of this stress path in which 

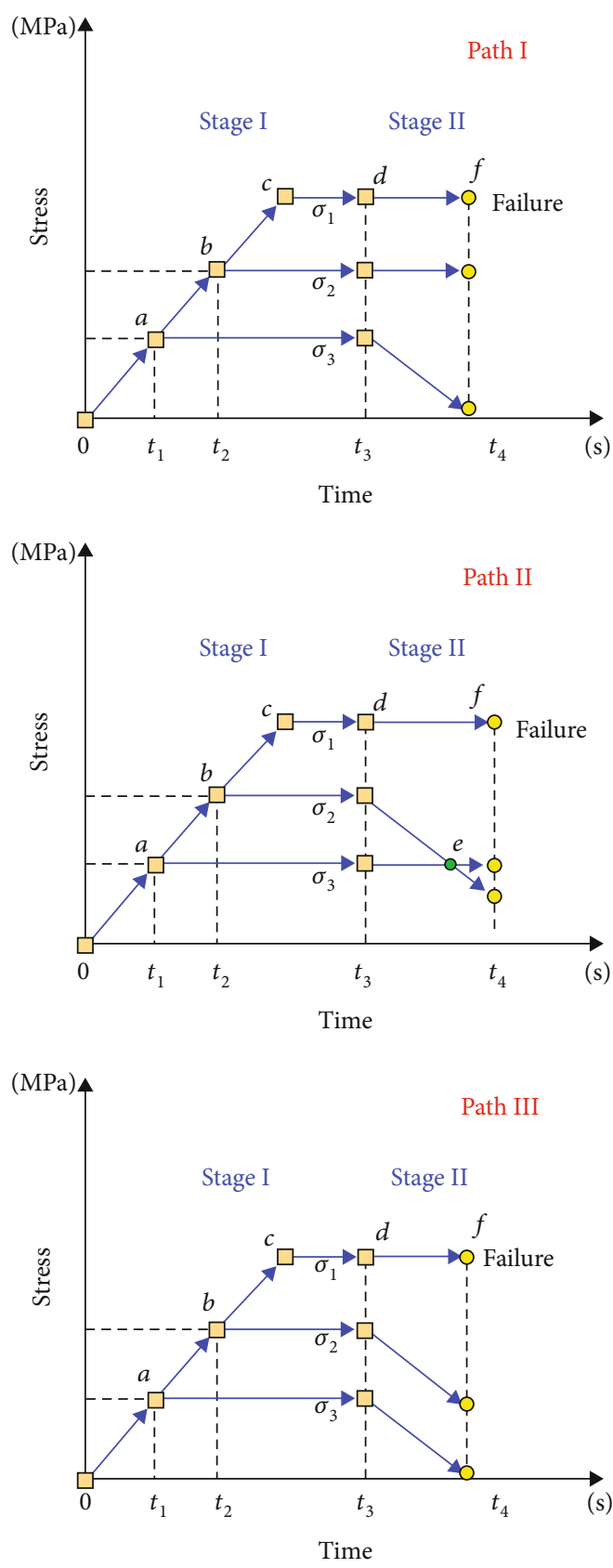

FIGURE 9: Typical loading and unloading scheme.

$\sigma_{2}$ is higher than $\sigma_{3}$, the fracture type of the specimen is similar to that under the other two stress paths and the macroscopic fracture plane is along the $\sigma_{2}$ direction. As $\sigma_{2}$ gradually decreases and becomes lower than $\sigma_{3}$, the $\sigma_{2}$ direction changes to the initial $\sigma_{3}$ direction and the complicated fracture network is found in the specimen in the initial $\sigma_{3}$ direction. From the above, the variation of the principal stress direction, especially the $\sigma_{2}$ direction, has a significant impact on the macroscopic failure characteristics of the specimen. The macroscopic failure plane highly depends on the $\sigma_{2}$ direction. This provides an important theoretical basis for the fracture evolution of the rock mass at the field site.

\section{Engineering Application}

The surrounding rock mass of the underground entry normally contains certain macroscopic and microscopic fractures. Entry excavation changes both the magnitudes and the direction of the principal stress and enhances the development of the fractures in the rock mass. This significantly affects the stability of the entry. The Griffith strength theory assumes that a material contains numbers of randomly distributed internal elliptical microcracks. As shown in Figure 13, a single microcrack is considered. It is deemed that the initiation of the microcracks inside of the rock is caused by the local tensile stress concentration induced at the microcrack tips. The normal stress and the tangential stress at the microcrack surface are calculated by [35]

$$
\left\{\begin{array}{l}
\sigma_{x}=\frac{1}{2}\left[\left(\sigma_{1}+\sigma_{3}\right)+\left(\sigma_{1}-\sigma_{3}\right) \cos 2 \beta\right], \\
\tau_{x y}=\frac{1}{2}\left(\sigma_{1}-\sigma_{3}\right) \sin 2 \beta,
\end{array}\right.
$$

where $\beta$ is the tip angle of the microcrack. The tip angle at which the microcrack is most likely to initiate can be derived by

$$
\beta=\frac{1}{2} \arccos \frac{\sigma_{1}-\sigma_{3}}{2\left(\sigma_{1}+\sigma_{3}\right)} .
$$

Based on the true triaxial compression tests in this study, the microcrack plane propagates along the $\sigma_{2}$ direction if $\sigma_{2}$ is higher than $\sigma_{3}$. This suggests that the rock mainly fractures at the $\sigma_{1}-\sigma_{3}$ surface at the dip angle calculated by Equation (5) during entry excavation. The fracture evolution characteristics of the rock at the roof surface are obtained in Figure 14 based on the Griffith strength theory. Both the magnitude and the direction of the principal stress in the roof rock mass vary due to the advance of the working face. This leads to the change of the dip angle at which the fracture is most likely to initiate. This dip angle gradually rotates towards the horizontal direction, and finally, a horizontal macroscopic fracture forms. In this situation, the roof strata tend to dislocate horizontally and roof collapse is likely to happen. This is similar to that occurring in the roof mass at the field site. The disturbance of entry excavation leads to the gradual interaction of the fractures at the roof surface. These fractures connect with each other to generate macroscopic fracture planes, and complicated fracture networks form due to the change of the dip angle at which the fracture is most likely to initiate. This is the basic reason for the roof failure of underground entries [36].

Based on the above analysis, the change of the stress condition in the roof rock mass during entry excavation is essentially the variation of the magnitudes and the directions of the principal stresses in the roof rock mass. The mechanical parameters of the roof rock mass are affected and degraded due to the complex evolution of the stress path and the stress direction caused by the disturbance of entry excavation. The dynamic damage evolution process is the basic reason for the 


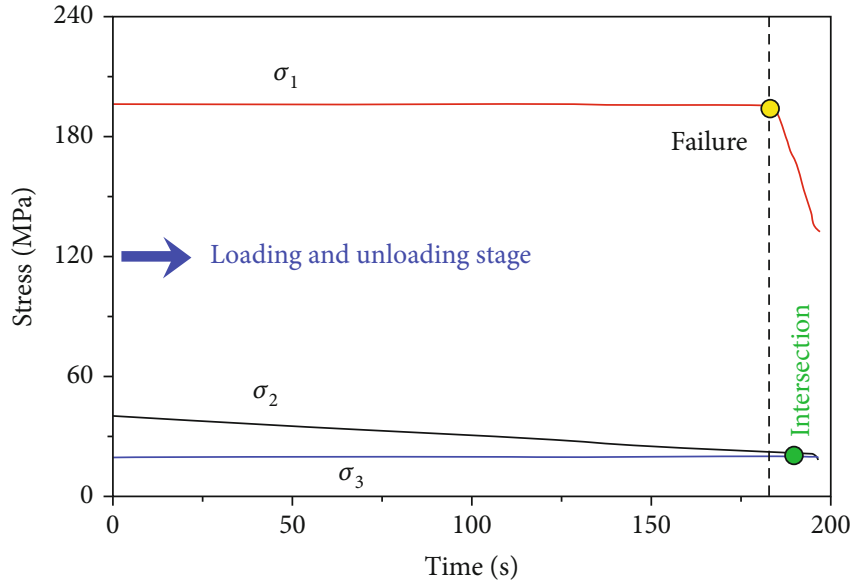

(a)

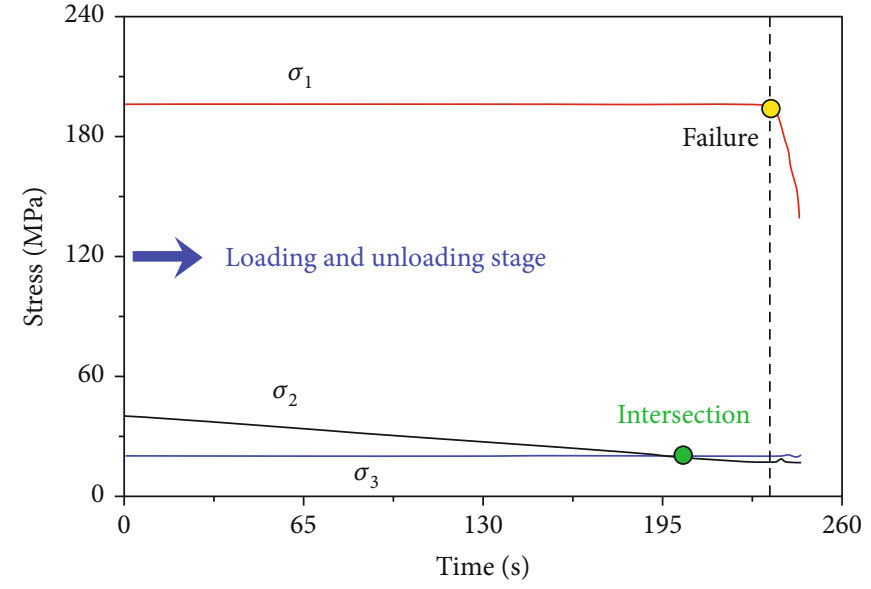

(b)

FIGURE 10: Stress-time curves of two groups of rocks in phase II (df) under path II.

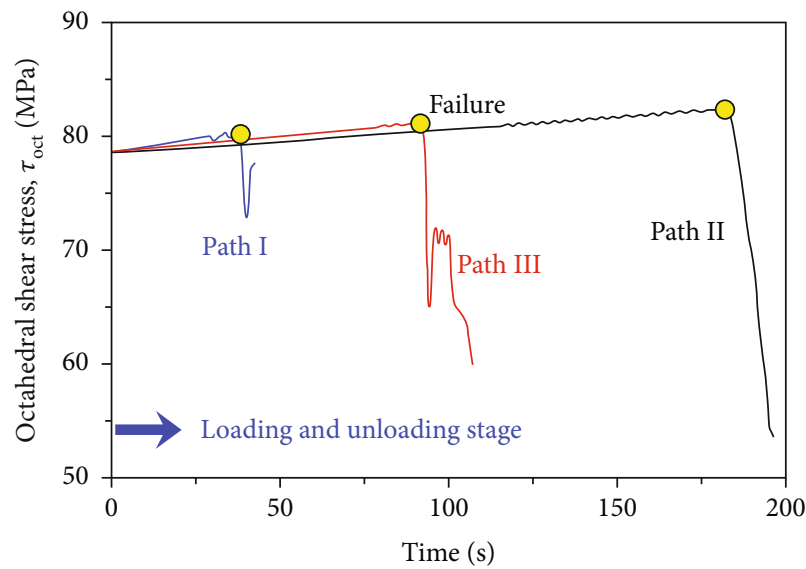

(a)

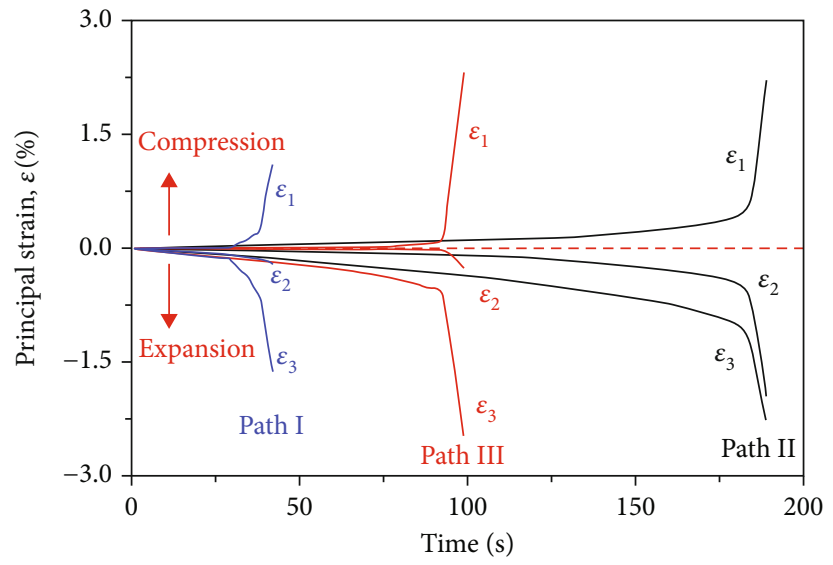

(b)

FIGURE 11: Stress-time curves of two groups of rocks during the unloading stage under path II.

deformation and fracture of the surrounding rock mass of the entry. The numerical modelling software ABAQUS is used to establish the two-dimensional numerical model of the mining entry at the 1306 working face. This is to analyze the plastic zone development around the entry induced by the variation of the magnitude and direction of the principal stress in the surrounding rock mass. The stress softening Mohr-Coulomb model is adopted in the numerical simulation. The entry dimensions and the mechanical parameters of the surrounding rock mass are consistent with those in the numerical model in Figure 2. The vertical in situ stress and the horizontal in situ stress are $15 \mathrm{MPa}$ and $10 \mathrm{MPa}$, respectively.

After the excavation of the 1305 head entry, relatively large plastic zones form at the sides of the entry (Figure 15(a)). With the advance of the working face, the roof rock mass collapses. After that, the 1306 tail entry is excavated (Figure 15(b)). Both the protective pillar and the entry side close to the pillar are seriously damaged. Note that the magnitudes and the directions of the in situ stresses applied to the model boundaries are constant in the numerical simulation. In Figures 15(c) and $15(\mathrm{~d})$, the magnitudes of the in situ stresses remain unchanged while their directions are rotated by $10^{\circ}$ and $20^{\circ}$, respectively. It is found that plastic zones occur at the corners of the entry and the plastic zones extend as the rotation angles increase.

Based on the results in Figures 14 and 15, horizontal failure planes form at the roof due to entry excavation. The roof strata tend to dislocate and collapse due to the rotation of the principal stress directions. The corners of the entry are highly influenced by the principal stress direction rotation, and the support in these areas should be strengthened. According to the dynamic variation of the magnitudes and directions of the principal stresses in the roof rock mass during entry excavation, the fracture characteristics of the surrounding rock mass at the entry roof, and the field condition at the entry excavation working face, the support scheme for the roof and the corners of the entry is given in Figures 16 and 17. The field experience shows that this support scheme achieves good results (Figure 18).

A shallow reinforcement area is generated at the entry roof by metal mesh, steel belts, and rock bolts. Largediameter cable bolts are installed into the hard rock strata to form the deep reinforcement area. The coupled shallow 


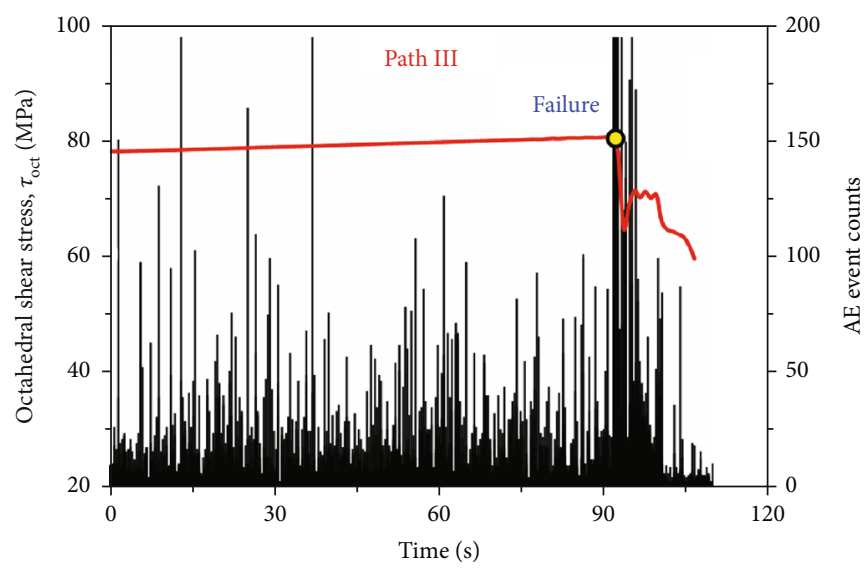

(a)

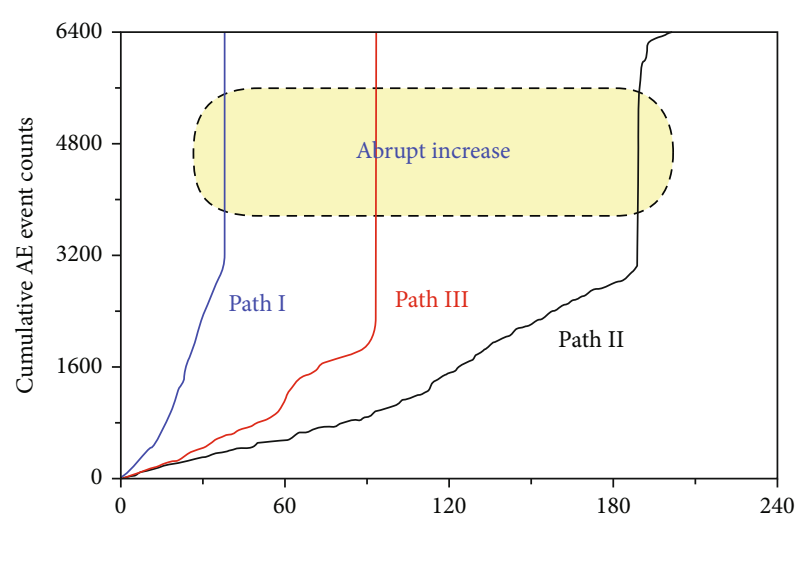

(b)

FIgURE 12: Variation of acoustic emission parameters of rocks under typical stress paths.

TABLE 3: Fracture characteristics of rocks under different true triaxial loading and unloading conditions.

Along the direction of $\sigma_{2}$ (initial direction)

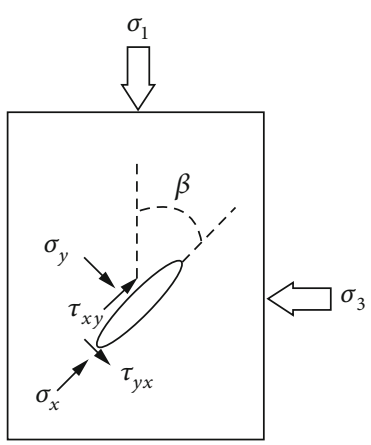

FIGURE 13: Schematic of a single microcrack.

and deep reinforcement prevents the horizontal dislocation and collapse of the roof strata. Rhomboid metal mesh is used to support the roof. Steel belts are arranged at a spacing of $800 \mathrm{~mm}$. In each row, 7 rock bolts with dimensions $22 \mathrm{~mm}$ (in diameter) $\times 2400 \mathrm{~mm}$ (in length) are used with a spacing of $750 \mathrm{~mm}$. The row spacing of the rock bolts is $800 \mathrm{~mm}$. The rock bolts at the ends of each row have the dip angle of $75^{\circ}$, while others are installed vertically. In each row, two cable bolts are installed. Each cable bolt has dimensions of $22 \mathrm{~mm}$ (in diameter) $\times 8500 \mathrm{~mm}$ (in length) and is $750 \mathrm{~mm}$ to the entry center. The row spacing of the cable bolts is $1600 \mathrm{~mm}$.

As for the entry side close to the protective pillar, 5 rock bolts are used in each row with dimensions of $20 \mathrm{~mm}$ (in diameter) $\times 2000 \mathrm{~mm}$ (in length). The top rock bolt in each row is about $200 \mathrm{~mm}$ to the steel belt with a dip angle of $15^{\circ}$ to $25^{\circ}$, while the bottom rock bolt is about $500 \mathrm{~mm}$ to the roof with a depression angle of $15^{\circ}$ to $25^{\circ}$. The other rock bolts are installed horizontally into the pillar with a spacing of $800 \mathrm{~mm}$. Two cable bolts with the diameter of $22 \mathrm{~mm}$ are installed in each row (between the rock bolt rows) with the row spacing of $1600 \mathrm{~mm}$. In each row, the top cable bolt (5 $\mathrm{m}$ in length) is $500 \mathrm{~mm}$ to the roof with a dip angle of $25^{\circ}$ to $35^{\circ}$ and the bottom cable bolt (3.5 $\mathrm{m}$ in length) is installed horizontally at the middle of the entry side. 

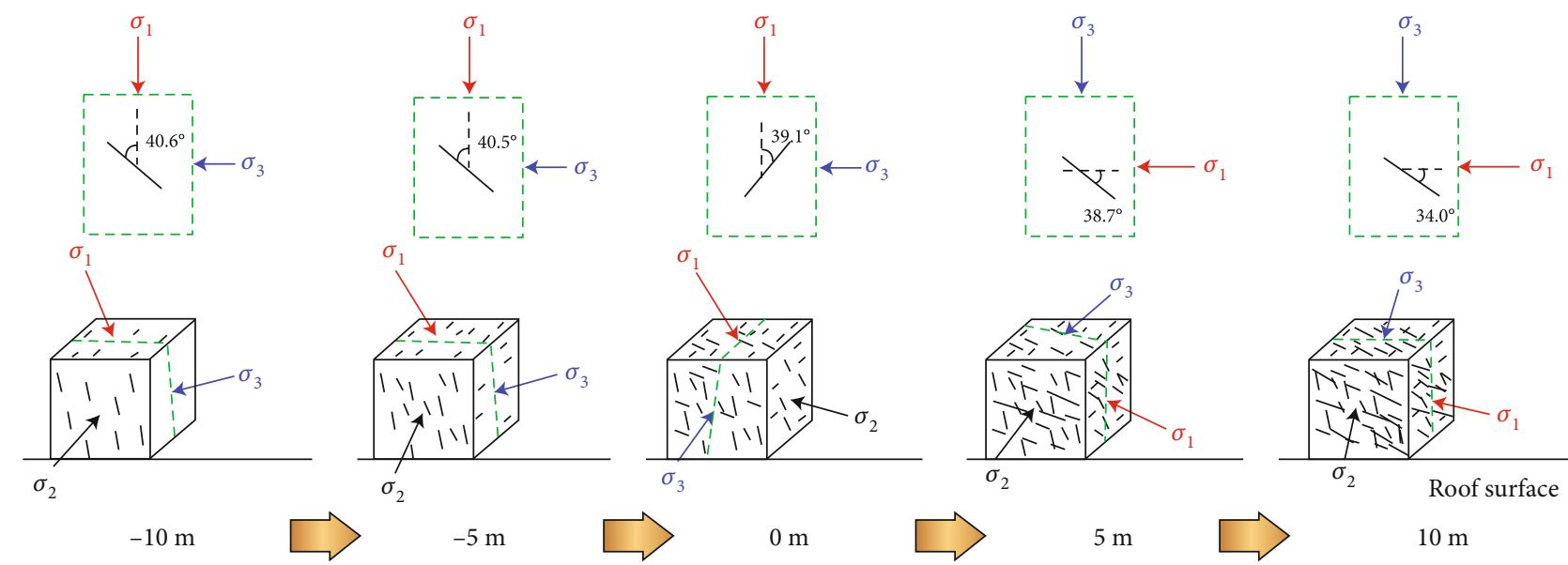

Figure 14: Variation of fracture development at the roof surface at different excavation distances.

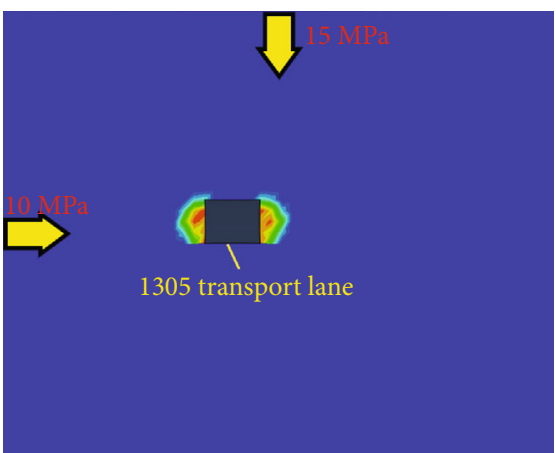

(a)

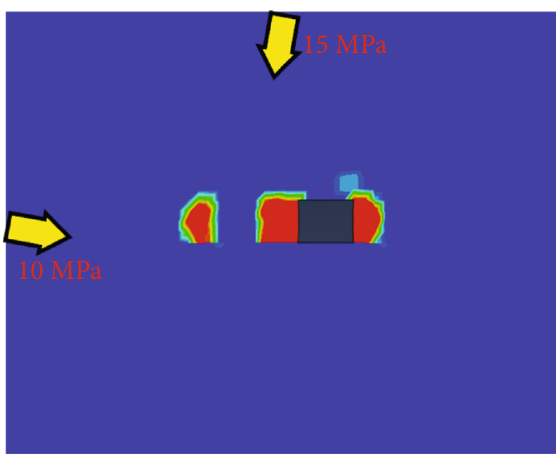

(c)

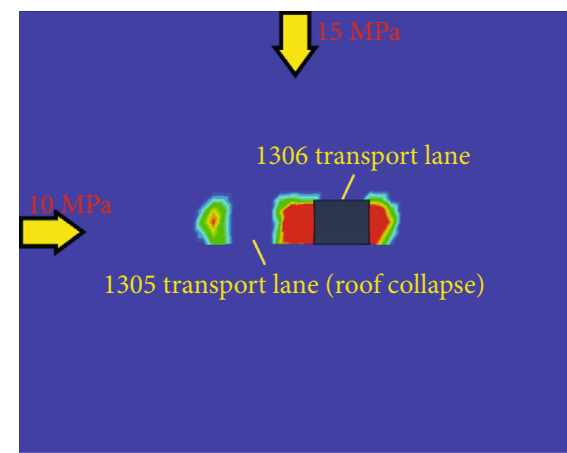

(b)

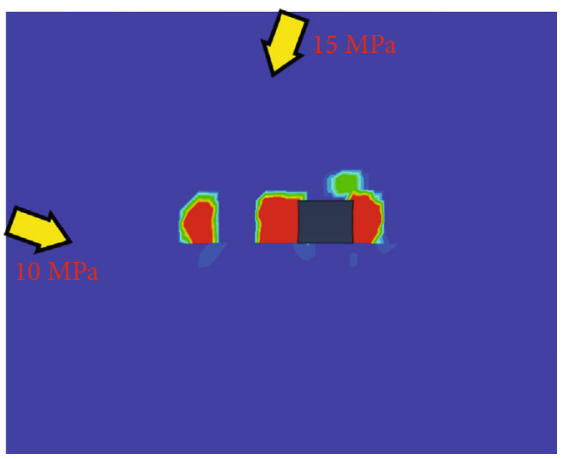

(d)

FIGURE 15: Variation of plastic zones in the surrounding rock mass of the entry: (a) damage of the 1305 head entry; (b-d) 1306 transport lane destruction, wherein the angle of the principal stress rotation is $0^{\circ}, 10^{\circ}$, and $20^{\circ}$, respectively.

The rock bolting at the solid coal side is the same as that at the protective pillar side. In addition, two cable bolts are used in each row with the row spacing of $1600 \mathrm{~mm}$. The cable bolt has dimensions of $22 \mathrm{~mm}$ (in diameter) $\times 8500 \mathrm{~mm}$ (in length). In each row, the top cable bolt is $500 \mathrm{~mm}$ below the top rock bolt at a dip angle of $15^{\circ}$ to $25^{\circ}$. The bottom cable bolt is horizontally installed at the middle of the side.

\section{Conclusions}

The variation of the stress condition in the roof rock mass during entry excavation and its influence on entry stability are systematically studied in this study. The impact of the change of the three-dimensional stress field on the fracture evolution of the roof rock mass is disclosed. The following conclusions are made.

(1) The surrounding rock mass at the entry roof is mainly influenced by the combined effect of the stress unloading and stress transference induced by entry excavation. The magnitude and the direction of the principal stress change notably, and this variation becomes different if the rock mass is away from the roof surface. The rotation of the principal stress 


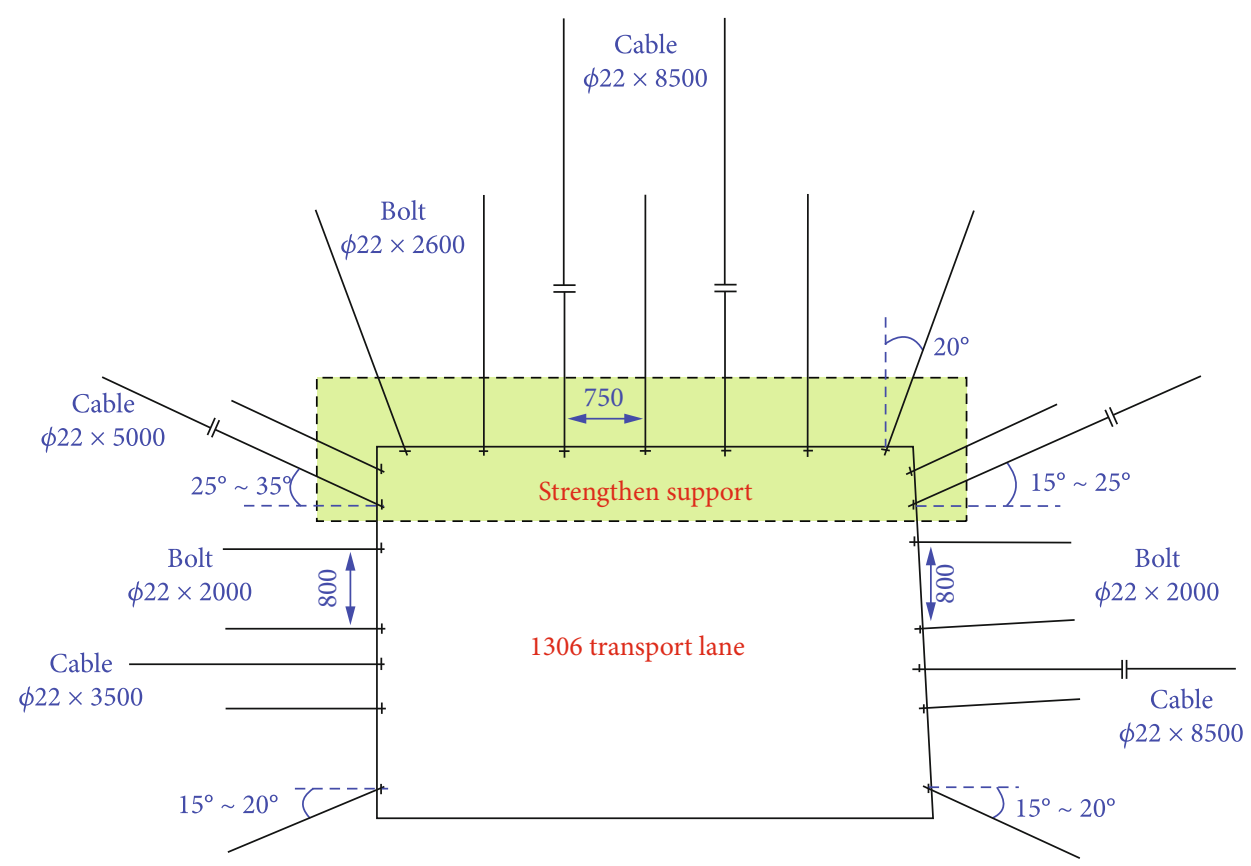

FIgURE 16: Supporting scheme of the gob-side entry.

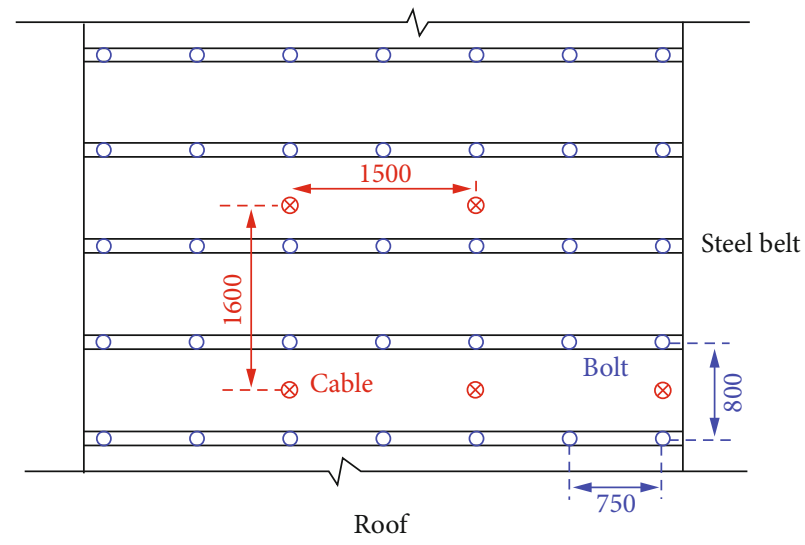

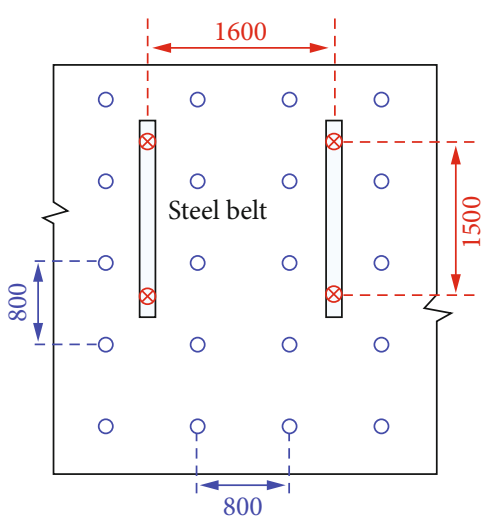

Protection coal pillar

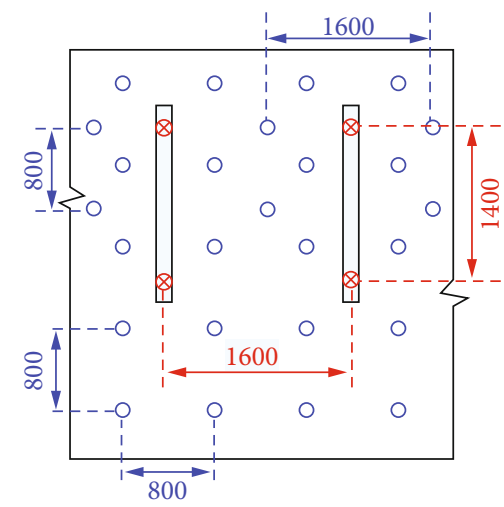

Solid coalside

Figure 17: Arrangement of rock bolts and cable bolts in the gob-side entry.

directions at the three monitoring elements around the roof surface is observed. A servo-controlled true triaxial material testing system is used to conduct true triaxial loading and unloading tests under different stress paths. And based on AE monitoring, the $\mathrm{AE}$ events are active during the unloading of the 


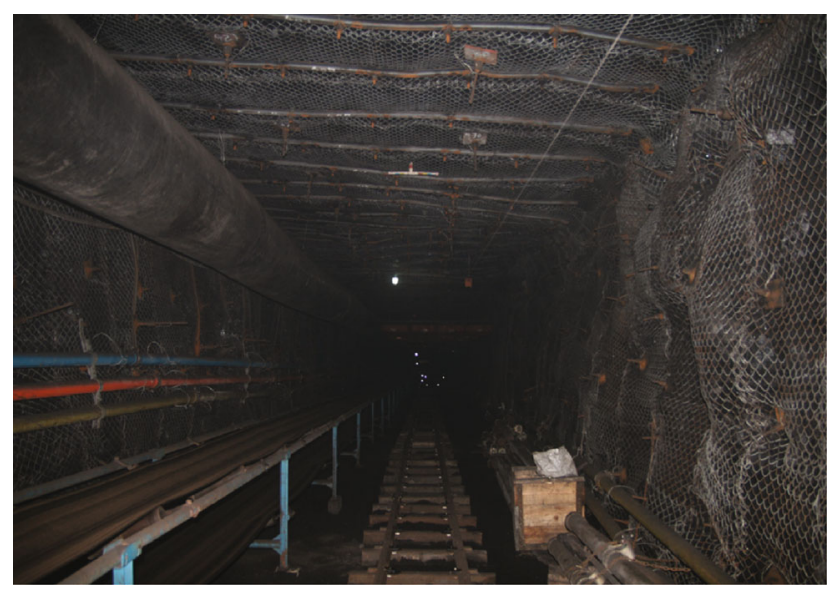

Figure 18: Good result of the support scheme.

specimen and obvious brittle failure of the specimen is observed

(2) The specimens under different stress paths have macroscopic "V"-shaped fracture planes (which stretch through the specimens) along the $\sigma_{2}$ direction, and the brittle failure characteristic of the specimen is obvious. However, when $\sigma_{2}$ and $\sigma_{3}$ exchange with each other (i.e., path II), a quite dense " $X$ "-shaped fracture network is found in the specimen along the $\sigma_{3}$ direction. This indicates that the change of the principal stress direction has a significant impact on the macroscopic fracture characteristics of the specimen. The macroscopic fracture plane highly depends on the intermediate principal stress. This provides an important basis for the investigation on the fracture evolution of the rock mass at the field site

(3) Based on the stress path experiments and the Griffith strength theory, the fracture evolution of the surrounding rock mass at the entry roof during entry excavation is studied. It is found that the variation of the principal stress direction in the surrounding rock mass of the entry has an extremely negative impact on the stability of the rock mass. The disturbance of entry excavation leads to the interaction of the fractures in the roof rock mass and the formation of the macroscopic fracture planes. Due to the change of the fracture propagation directions, relatively complex fracture networks are generated in the surrounding rock mass of the entry. In this situation, the roof strata are likely to dislocate horizontally and collapse and the corners of the entry are seriously damaged. This is the fundamental reason for the failure of the surrounding rock mass of the entry. Based on the findings, a support scheme is proposed. The field experience shows that the support scheme can achieve good results

\section{Data Availability}

The data used to support the findings of this study are available from the corresponding author upon request.

\section{Conflicts of Interest}

No conflict of interest exists in the submission of this manuscript.

\section{Authors' Contributions}

The manuscript is approved by all the authors for publication.

\section{Acknowledgments}

We gratefully acknowledge the support provided by the School Basic Scientific Research Operating Expenses Project (2017XKQY097).

\section{References}

[1] H. Jia, K. Pan, S. Liu, B. Peng, and K. Fan, "Evaluation of the mechanical instability of mining roadway overburden: research and applications," Energies, vol. 12, no. 22, p. 4265, 2019.

[2] B. Shen, A. King, and H. Guo, "Displacement, stress and seismicity in roadway roofs during mining-induced failure," International Journal of Rock Mechanics and Mining Sciences, vol. 45, no. 5, pp. 672-688, 2008.

[3] H. Yan, F. He, T. Yang, L. Li, S. Zhang, and J. Zhang, "The mechanism of bedding separation in roof strata overlying a roadway within a thick coal seam: a case study from the Pingshuo Coalfield, China," Engineering Failure Analysis, vol. 62, pp. 75-92, 2016.

[4] Y. Yuan, W. Wang, S. Li, and Y. Zhu, "Failure mechanism for surrounding rock of deep circular roadway in coal mine based on mining-induced plastic zone," Advances in Civil Engineering, vol. 2018, Article ID 1835381, 14 pages, 2018.

[5] Z. Zhu, C. Zhu, and H. Yuan, "Distribution and evolution characteristics of macroscopic stress field in gob-side entry retaining by roof cutting," Geotechnical and Geological Engineering, vol. 37, pp. 2963-2976, 2019.

[6] F. Wang, C. Duan, S. Tu, N. Liang, and Q. Bai, "Hydraulic support crushed mechanism for the shallow seam mining face under the roadway pillars of room mining goaf," International Journal of Mining Science and Technology, vol. 27, no. 5, pp. 853-860, 2017.

[7] P. K. Kaiser, S. Yazici, and S. Maloney, "Mining-induced stress change and consequences of stress path on excavation stability - a case study," International Journal of Rock Mechanics and Mining Sciences, vol. 38, no. 2, pp. 167-180, 2001.

[8] B. Wang, F. Dang, W. Chao, Y. Miao, J. Li, and F. Chen, "Surrounding rock deformation and stress evolution in pre-driven longwall recovery rooms at the end of mining stage," International Journal of Coal Science \& Technology, vol. 6, no. 4, pp. 536-546, 2019.

[9] X. Xia, H. B. Li, J. C. Li, B. Liu, and C. Yu, “A case study on rock damage prediction and control method for underground tunnels subjected to adjacent excavation blasting," Tunnelling and Underground Space Technology, vol. 35, pp. 1-7, 2013.

[10] M. S. Diederichs, P. K. Kaiser, and E. Eberhardt, "Damage initiation and propagation in hard rock during tunnelling and the influence of near-face stress rotation," International Journal of Rock Mechanics and Mining Sciences, vol. 41, no. 5, pp. 785812,2004 
[11] H. Xie, F. Gao, and Y. Ju, "Research and development of rock mechanics in deep ground engineering," Chinese Journal of Rock Mechanics and Engineering, vol. 34, pp. 2161-2178, 2015.

[12] E. Eberhardt, "Numerical modelling of three-dimension stress rotation ahead of an advancing tunnel face," International Journal of Rock Mechanics and Mining Sciences, vol. 38, no. 4, pp. 499-518, 2001.

[13] N. Liu, C. Zhang, X. Chen, J. Hou, and W. Chu, "Monitoring and characteristics study of stress evolution of surrounding rock during deep tunnel excavation," Chinese Journal of Rock Mechanics and Engineering, vol. 30, pp. 1729-1737, 2011.

[14] S.-Q. Yang, P. Ranjith, and Y.-L. Gui, "Experimental study of mechanical behavior and X-ray micro CT observations of sandstone under conventional triaxial compression," Geotechnical Testing Journal, vol. 38, pp. 179-197, 2015.

[15] S. Wang, X. Li, K. Du, S. Wang, and M. Tao, "Experimental study of the triaxial strength properties of hollow cylindrical granite specimens under coupled external and internal confining stresses," Rock Mechanics and Rock Engineering, vol. 51, no. 7, pp. 2015-2031, 2018.

[16] I. Janeček and D. A. Mishra, "Deformational response of rocks to uniaxial, biaxial, and triaxial loading or unloading regimes," Procedia Engineering, vol. 191, pp. 332-341, 2017.

[17] X. Li, F. Feng, D. Li, K. Du, P. G. Ranjith, and J. Rostami, "Failure characteristics of granite influenced by sample height-towidth ratios and intermediate principal stress under truetriaxial unloading conditions," Rock Mechanics and Rock Engineering, vol. 51, no. 5, pp. 1321-1345, 2018.

[18] M. Cai, "Influence of intermediate principal stress on rock fracturing and strength near excavation boundaries-insight from numerical modeling," International Journal of Rock Mechanics and Mining Sciences, vol. 45, no. 5, pp. 763-772, 2008.

[19] Y. Cai, D. Liu, J. P. Mathews, and Z. Pan, "Permeability evolution in fractured coal - combining triaxial confinement with $\mathrm{X}$-ray computed tomography, acoustic emission and ultrasonic techniques," International Journal of Coal Geology, vol. 122, pp. 91-104, 2014.

[20] B.-Y. Jiang, S.-T. Gu, L.-G. Wang, G.-C. Zhang, and W.-S. Li, "Strainburst process of marble in tunnel-excavation-induced stress path considering intermediate principal stress," Journal of Central South University, vol. 26, no. 4, pp. 984-999, 2019.

[21] J. Ptacek, P. Konicek, L. Stas, P. Waclawik, and R. Kukutsch, "Rotation of principal axes and changes of stress due to mine-induced stresses," Canadian Geotechnical Journal, vol. 52, no. 10, pp. 1440-1447, 2015.

[22] X. Li, S. Wang, and S. Wang, "Experimental investigation of the influence of confining stress on hard rock fragmentation using a conical pick," Rock Mechanics and Rock Engineering, vol. 51, no. 1, pp. 255-277, 2018.

[23] Q. Ye, G. Wang, Z. Jia, C. Zheng, and W. Wang, "Similarity simulation of mining-crack-evolution characteristics of overburden strata in deep coal mining with large dip," Journal of Petroleum Science and Engineering, vol. 165, pp. 477-487, 2018.

[24] Y. Li, C. Wu, and B.-A. Jang, "Effect of bedding plane on the permeability evolution of typical sedimentary rocks under triaxial compression," Rock Mechanics and Rock Engineering, vol. 53, no. 11, pp. 5283-5291, 2020.

[25] W. Xu, E. Wang, R. Shen, D. Song, and J. Zhang, "Distribution pattern of front abutment pressure of fully-mechanized work- ing face of soft coal isolated island," International Journal of Mining Science and Technology, vol. 22, no. 2, pp. 279-284, 2012.

[26] C. Zhang, H. Zhou, X. Feng, L. Xing, and S. Qiu, "Layered fractures induced by principal stress axes rotation in hard rock during tunnelling," Materials Research Innovations, vol. 15, pp. s527-s530, 2013.

[27] S. R. Zhang and L. H. Liang, "Analysis on tunnel liner supporting time considering three-dimensional stress rotation," Journal of Hydraulic Engineering, vol. 38, pp. 704-709, 2007.

[28] R. S. Read, N. A. Chandler, and E. J. Dzik, "In situ strength criteria for tunnel design in highly-stressed rock masses," International Journal of Rock Mechanics and Mining Sciences, vol. 35, no. 3, pp. 261-278, 1998.

[29] L. Weng, X. Li, and M. Tao, "Influence of geostress orientation on fracture response of deep underground cavity subjected to dynamic loading," Shock and Vibration, vol. 2015, Article ID 575879, 9 pages, 2015.

[30] R. K. S. Wong, "Sand sheared by stresses with cyclic variations in direction," Geotechnique, vol. 36, no. 2, pp. 215-226, 1986.

[31] H. Jia, G. Li, L. Wang, and A. Qiao, "Characteristics of stressfield environment and roof falling mechanism of mining influenced roadway," Journal of Mining \& Safety Engineering, vol. 34, pp. 707-714, 2017.

[32] Z. Li, L. Wang, Y. Lu, W. Li, and K. Wang, "Experimental investigation on the deformation, strength, and acoustic emission characteristics of sandstone under true triaxial compression," Advances in Materials Science and Engineering, vol. 2018, Article ID 5241386, 16 pages, 2018.

[33] X. Ma, J. W. Rudnicki, and B. C. Haimson, "Failure characteristics of two porous sandstones subjected to true triaxial stresses: applied through a novel loading path," Journal of Geophysical Research: Solid Earth, vol. 122, no. 4, pp. 2525-2540, 2017.

[34] Q. He, Y. Li, D. Li, and C. Zhang, "Microcrack fracturing of coal specimens under quasi-static combined compressionshear loading," Journal of Rock Mechanics and Geotechnical Engineering, vol. 12, no. 5, pp. 1014-1026, 2020.

[35] Z. Li, L. Wang, Y. Lu, W. Li, K. Wang, and H. Fan, "Experimental investigation on true triaxial deformation and progressive damage behaviour of sandstone," Scientific Reports, vol. 9, p. 3386, 2019.

[36] Y. Xue, T. Teng, F. Dang, Z. Ma, S. Wang, and H. Xue, "Productivity analysis of fractured wells in reservoir of hydrogen and carbon based on dual-porosity medium model," International Journal of Hydrogen Energy, vol. 45, no. 39, pp. 20240-20249, 2019. 